\title{
Climate Responsive Design and the Milam Residence
}

\author{
Carl Fiocchi ${ }^{1}$, Simi Hoque ${ }^{1, *}$ and Mohammad Shahadat ${ }^{2}$ \\ 1 Department of Environmental Conservation, University of Massachusetts, Amherst, \\ MA 01003, USA; E-Mail: fiocchi@eco.umass.edu \\ 2 Architecture and Design, University of Massachusetts, Amherst, MA 01003, USA; \\ E-Mail:mshahada@art.umass.edu
}

* Author to whom correspondence should be addressed; E-Mail: simih@eco.umass.edu; Tel.: +1-413-545-1866; Fax: +1-413-545-4358.

Received: 29 September 2011 / Accepted: 9 November 2011 / Published: 21 November 2011

\begin{abstract}
Energy conservation and efficiency is an essential area of focus in contemporary building design. The perception that the designers of buildings during the Modernist period of architecture ignored these principles is a false one. The present study, an examination of Paul Rudolph's Milam Residence, a masterpiece of American residential architecture, is part of a larger project endeavoring to create a knowledge base of the environmental performance of iconic modernist homes. A critical examination of the Milam House allows insight into specific design characteristics that impact energy efficiency and conservation. Located in Ponte Vedra Beach, Florida, the Milam Residence was constructed in 1962. It was the last of a series of Florida residences designed by Rudolph, Chairman of the Department of Architecture at Yale University (1958-1965). The structure's form is strongly related to its location on a subtropical beachfront. This paper presents a detailed analysis of the building's solar responsiveness. Specifically, we examine design strategies such as orientation and sunscreening and their effect on daylighting, shading, and heat gain. The analysis is based on parametric energy modeling studies using Autodesk's Ecotect, an environmental analysis tool that allows simulation of building performance. While the initial target of the program was early design, the program allows the input of complex geometries and detailed programming of zones, materials, schedules, etc. The program's excellent analyses of desired parameters are augmented by visualizations that make it especially valuable in communicating results. Our findings suggest that the building, as built and situated on the site, does take advantage of daylighting and solar shading and does so in both expected and unexpected ways.
\end{abstract}


Keywords: climate responsive design; energy modeling; Milam Residence

\section{Introduction}

The Milam Residence, located in Ponte Vedra Beach, Florida, was designed by Paul Rudolph in 1962. The last of a series of Florida residences built by Rudolph, the modernist structure contains stylistic elements of the Sarasota School while also hinting at the more monolithic, monumentalist or brutalist style later developed by Rudolph [1]. Built primarily of concrete and glass and located in a subtropical climate, at first glance the building might not appear to be designed with attention to energy conservation. The residence is oriented to the east rather than the south, the residence is air-conditioned, and windows are inoperable.

The building is primarily constructed of poured concrete and concrete blocks and has extensive window glazing, especially on the east façade. While this glazing makes up a majority of the easternmost façade, all other sides of the building contain minimal transparent surfaces. For the exterior envelope, Rudolph's use of concrete blocks appears to allow for structural freedom while also responding to the local climate.

This paper provides an analysis of the house with regard to its climate responsiveness, focusing specifically on daylighting, shading, heat gain, and cooling loads. The objective is to assess the Milam Residence's design to quantify how it is impacted by solar insolation and to provide insights about design characteristics that influence efficiency and conservation.

The Milam Residence (Figure 1, [2]) is located off the northeast shore of Florida in the midst of suburban residences outside of Jacksonville. Rudolph's early work, much of which was completed with partner and mentor Ralph Twitchell, falls within the Sarasota School of Modern Architecture, which took into account regional climate and cultural influences in residential construction styles and techniques [3].

Figure 1. The Milam residence.

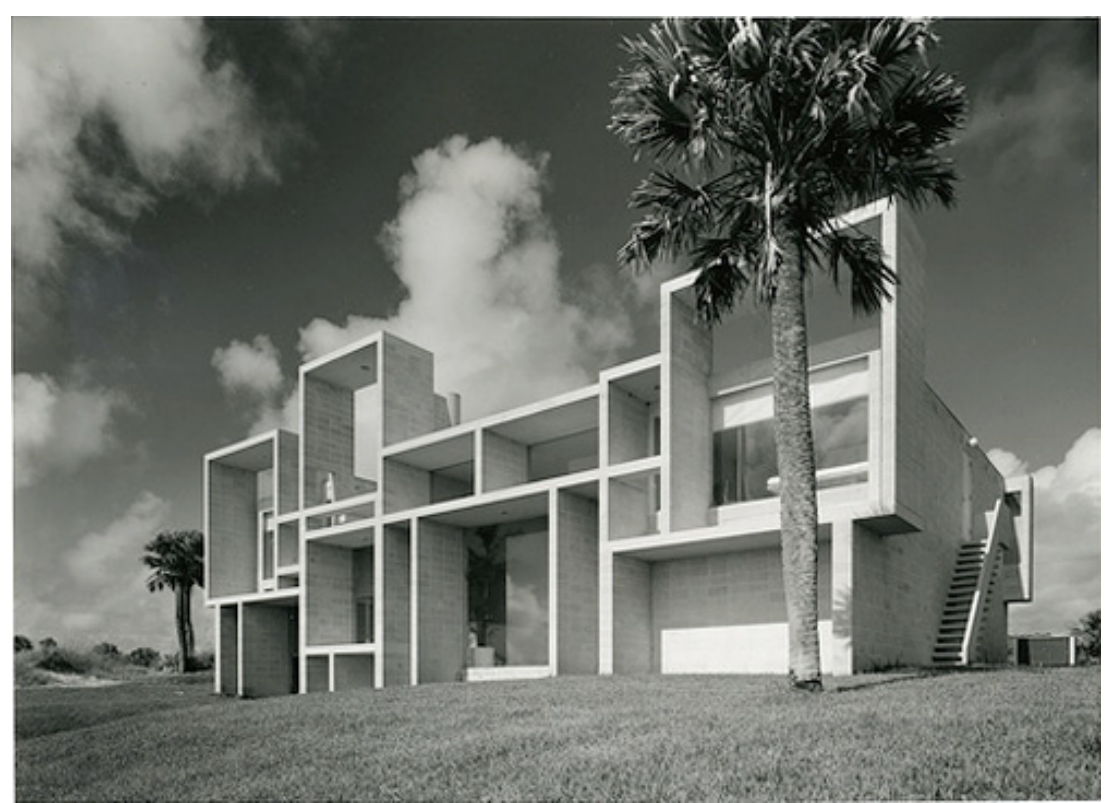


This regional modernism is seen within works of other architects working in the area at the time, such as Lundy, Twitchell, and Siebert. These architects often utilized regional materials in construction, relied upon culturally familiar or traditional building forms, and maintained strong relationships between structures and local landscapes. As such, previous Floridian houses designed by Rudolph relied heavily on lightweight construction, a relationship with outdoor spaces, and regional architectural precedents, as well as the modular forms and new construction materials typical of the modernist movement [1].

Later works by Rudolph (such as the 1963 Yale School of Architecture) would move towards brutalism, using massive concrete forms and blocks in an international, monumentalist style heavily inspired by Le Corbusier [4]. The Milam house lies somewhere between the extremes of Rudolph's stylistic spectrum. Built at the end of his association with the Sarasota School, the house is more solid and massive in feeling than his earlier residential works. The increased use of concrete block rather than wood or other local materials, large glass panes, and a modular floor plan are comparable to Rudolph's later work. However, the structure's relationship with outdoor space, interaction with light, and play between mass and void still evoke the lightweight feeling of earlier works within the Sarasota School.

Investigations of the Milam residence indicate that the structure is designed for the Floridian climate. The layout is an open plan (Figure 2, [5]) with room delineations largely marked by level changes, of which there are a total of seven. The interior floor plan revolves around a large living space which is sunken below the rest of the house [6]. It is the first of Rudolph's Florida residences to include central air conditioning. Cross ventilation through the spaces of the house is guided by the central air conditioning units rather than by the windows, which are inoperable [3].

Arthur Milam describes the house in correspondence to the authors (16 March 2011):

Regarding materials used in the project: all horizontal structures are poured-in place concrete (usually 8" in depth); all vertical structures are concrete block (usually 8" block; but 12" where load bearing requirements dictated); all glass (normally 3/8") were inserted directly into the horizontal and vertical beams so that there would be no break in the flow from glass to concrete (or concrete block). As you can see from photos of the east exposure, some of them are quite large (up to $10^{\prime} \times 12^{\prime}$ ).

The present study quantifies to what extent the design and orientation of the Milam Residence is adapted for the local climate and landscape. 
Figure 2. (a) Ground Floor; (b) Second Floor.

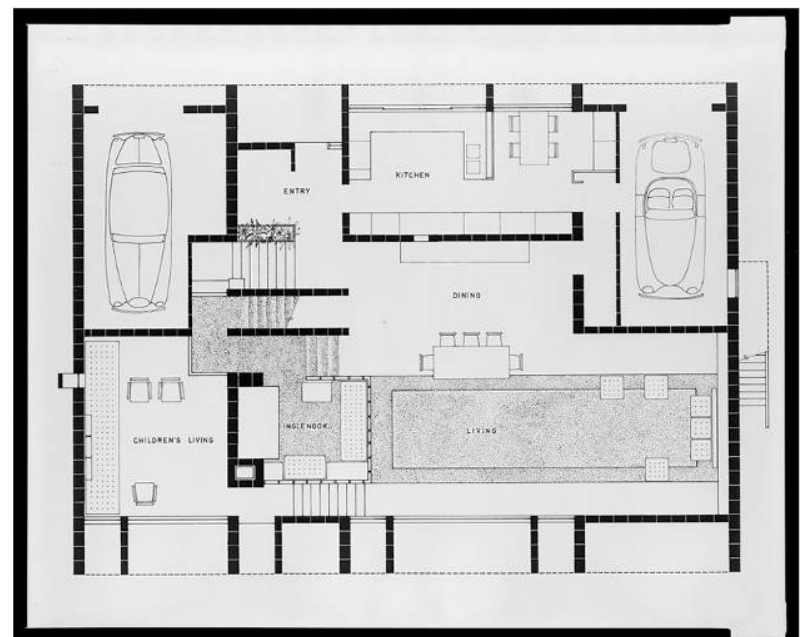

(a)

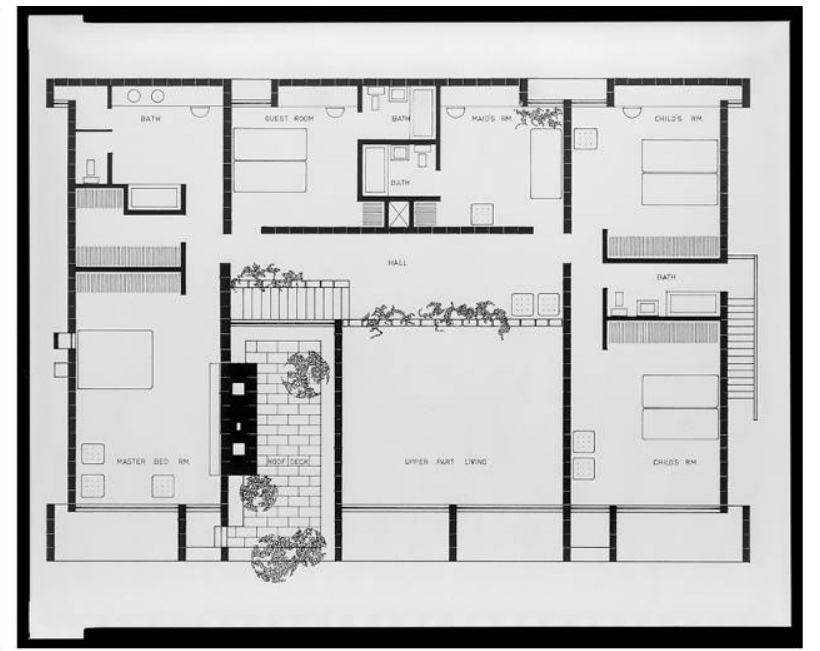

(b)

\section{Method}

The tool selected for this analysis is Autodesk's Ecotect. Ecotect is a parametric building performance simulation program that can execute analyses in several areas: thermal performance, solar exposure, lighting (daylight and artificial), material costs, resource consumption, and acoustics. An Ecotect model for solar exposure and daylighting requires precise geometries of envelope, overhangs, window openings, shading devices, and impacting features that affect the sun's light/shadow projection on the building such as adjacent building geometries or landscape features. Model precision is rewarded by the ability to examine in commensurate detail the actual light and shadow projection that falls on any surface interior or exterior, at any time (hour by hour) of the year based on the appropriately imported weather file and geopositioning. Additionally, for energy usage analysis the model's interior geometry should be complete with appropriate material inputs, HVAC equipment inputs, and schedule inputs.

The examination can be of any surface, e.g., a shadow pattern projected from an overhang on an exterior wall or window, light penetrating through a transparent façade, or insolation on a roof plane. Ecotect also displays the sun's path (daily or yearly) across the site (Figure 3). The model itself does not accurately reflect building materials because it is essentially a geometric model impregnated with invisible material and assembly data. Using this model, it is possible to examine specific solar energy data, e.g., the exact amount of insolation $\mathrm{kWh} / \mathrm{m}^{2}\left(\mathrm{Btu} / \mathrm{ft}^{2}\right)$ on any exterior elevation for a specified time period, the amount of insolation an interior thermal mass receives through a specific window on a façade, or the heating and cooling loads over a designated time period.

In this study, a detailed Ecotect model of the Milam Residence is created to examine the building's form and orientation in relation to the coastline and sun path. An assessment of the structure's geometry and spatial organization in relation to its orientation is used to demonstrate how interior spaces maximize natural lighting (Analysis I), how the eastern shading construction controls insolation impacts (Analysis II), and the effect of the shading construction on energy loads (Analysis III). 
Figure 3. Yearly sunpath for Milam Residence, Ecotect model.

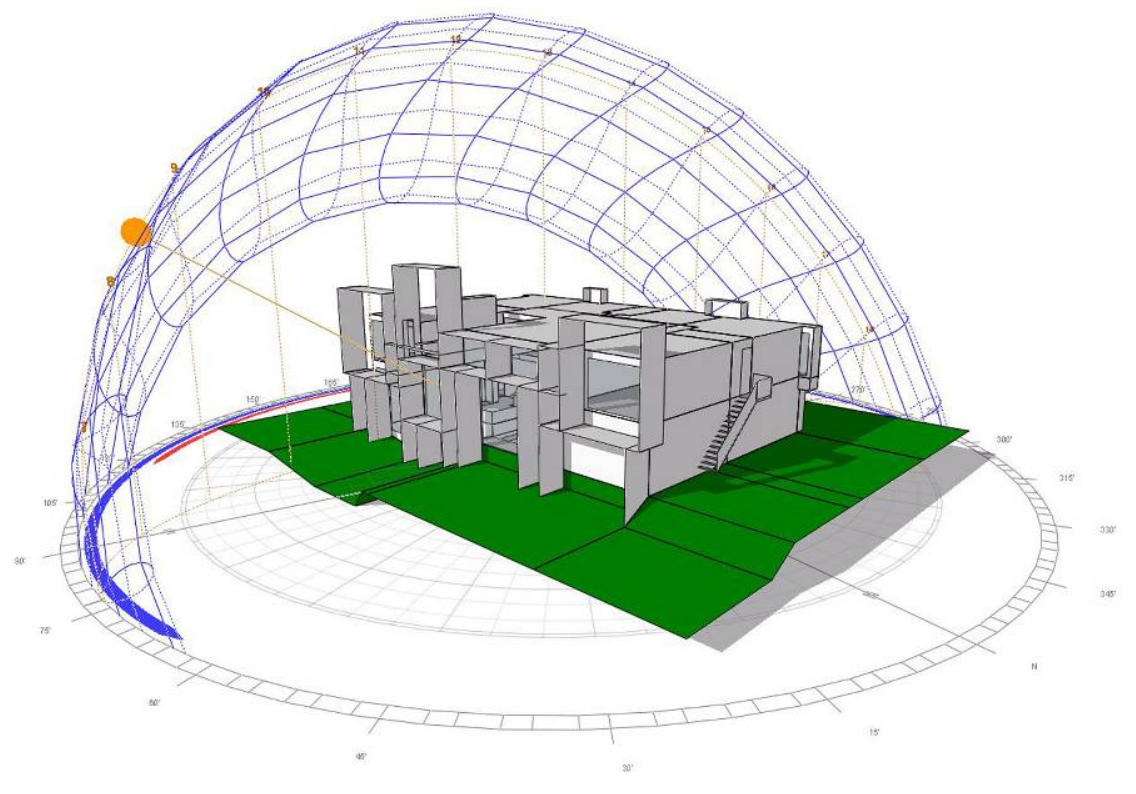

\subsection{Climate}

Understanding the climatic conditions of the Florida coast contextualizes the Milam Residence analysis. Ponte Vedra is located near Jacksonville in a coastal zone with a humid subtropical climate [7]. This entails mild winters, and hot, humid summers. Average high temperatures occur during July and August, peaking at a little over $32{ }^{\circ} \mathrm{C}\left(90^{\circ} \mathrm{F}\right)$ (Table 1, [7]). By contrast, the lowest temperatures fall between 4.4 and $15.5^{\circ} \mathrm{C}\left(40\right.$ and $\left.64{ }^{\circ} \mathrm{F}\right)$ and occur during January.

Table 1. Average monthly temperatures for Jacksonville, Florida 2010.

\begin{tabular}{|c|c|c|c|c|c|c|c|c|c|c|c|c|}
\hline Jacksonville Temperature & Jan. & Feb. & Mar. & Apr. & May & Jun. & Jul. & Aug. & Sep. & Oct. & Nov. & Dec. \\
\hline Avg. Temperature & 52.4 & 55.2 & 61.1 & 67.0 & 73.4 & 79.1 & 81.6 & 81.2 & 78.1 & 69.8 & 61.9 & 55.1 \\
\hline Avg. Max Temperature & 64.2 & 67.0 & 73.0 & 79.1 & 84.7 & 89.3 & 91.4 & 90.7 & 87.2 & 80.2 & 73.6 & 66.8 \\
\hline Avg. Min Temperature & 40.5 & 43.3 & 49.2 & 54.9 & 62.1 & 69.1 & 71.9 & 71.8 & 69.0 & 59.3 & 50.2 & 43.4 \\
\hline $\begin{array}{l}\text { Days with Max Temp of } 90^{\circ} \mathrm{F} \text { or } \\
\text { Higher }\end{array}$ & 0.0 & 0.0 & $<0.5$ & 1.0 & 8.0 & 17.0 & 24.0 & 21.0 & 10.0 & 1.0 & 0.0 & 0.0 \\
\hline Days with Min Temp Below Freezing & 5.0 & 3.0 & 1.0 & 0.0 & 0.0 & 0.0 & 0.0 & 0.0 & 0.0 & 0.0 & 1.0 & 4.0 \\
\hline
\end{tabular}

Heating and cooling degree days for Jacksonville indicate it is cooling dominant climate as a whole. The months with the highest number of cooling degree days fall between June and September. Because the focus is on cooling, we conducted solar shading and lighting analysis on a typical hot summer day, August 21st. The average hourly temperature during this day is presented in Table 2 [8]. 
Table 2. Average hourly temperature for August 21st for Jacksonville, Florida 2010.

\begin{tabular}{ccc}
\hline Time & $\begin{array}{c}\text { Average } \\
\text { Temperature }\end{array}$ & $\begin{array}{c}\text { Relative } \\
\text { Humidity }\end{array}$ \\
\hline 6:00 & 80.1 & 94 \\
7:00 & 80.1 & 94 \\
$8: 00$ & 80.1 & 94 \\
9:00 & 82.9 & 85 \\
$10: 00$ & 84.0 & 82 \\
$11: 00$ & 87.1 & 72 \\
$12: 00$ & 89.1 & 67 \\
$13: 00$ & 90.0 & 65 \\
$14: 00$ & 91.0 & 61 \\
$15: 00$ & 91.9 & 58 \\
16:00 & 93.9 & 52 \\
17:00 & 93.0 & 57 \\
\hline
\end{tabular}

\section{Analysis I: Daylighting Gains Resulting from Voids in Shading Screen Geometry}

The Milam Residence is oriented towards the ocean, which is to its east. On this façade, there is a significant amount of glazing directing the occupants view towards the view of the nearby ocean. A three dimensional "screening device" provides a frame for the view as well as outdoor seating. The shape of the screen for the upper level of the house is of interest. Is the design based on elementary shading principles with aesthetic contribution its main impetus or are there more sophisticated parameters dictating its form?

The tallest of screens, in the center, is the largest void. A private terrace with outdoor seating, accessible only from the master bedroom is located behind it. The proportions of the screen allow substantial penetration of eastern sunlight in the morning and the location of terrace in the lee of the building's eastern envelope provides shading from the western afternoon sunlight. This is apparent in the Ecotect model and presents a clear indication of Rudolph's insertion of elementary shading techniques into his effort at monumentality. Since the space is outdoors there is little impact on the cooling loads of the residence; the construct's main function is to provide a framing device for the view from the terrace and a focal apex for the buildings geometry especially when viewed from the east.

Similarly, all the other screens, save the upper level flanking screens, are absent of voids and offer a predictable and quantifiable shading advantage to the interiors. The Ecotect model substantiates the effect of the shading devices (Figures 4 and 5). In Figure 4 the insolation analysis is done both with and without the presence of the shading devices. Again, August 21st was selected as it is a day in deep summer when shading of the glazing surfaces is most desired to reduce solar gain. Without the shading device, solar loads are $163-218 \mathrm{Wh} / \mathrm{m}^{2}\left(6000-8000 \mathrm{Btu} / \mathrm{ft}^{2}\right)$ and with the shading device, loads are reduced to $41-136 \mathrm{Wh} / \mathrm{m}^{2}\left(1500-5000 \mathrm{Btu} / \mathrm{ft}^{2}\right)$. 
Figure 4. (a) August 21st-Insolation with shading screen; (b) August 21st-Insolation without shading screen.

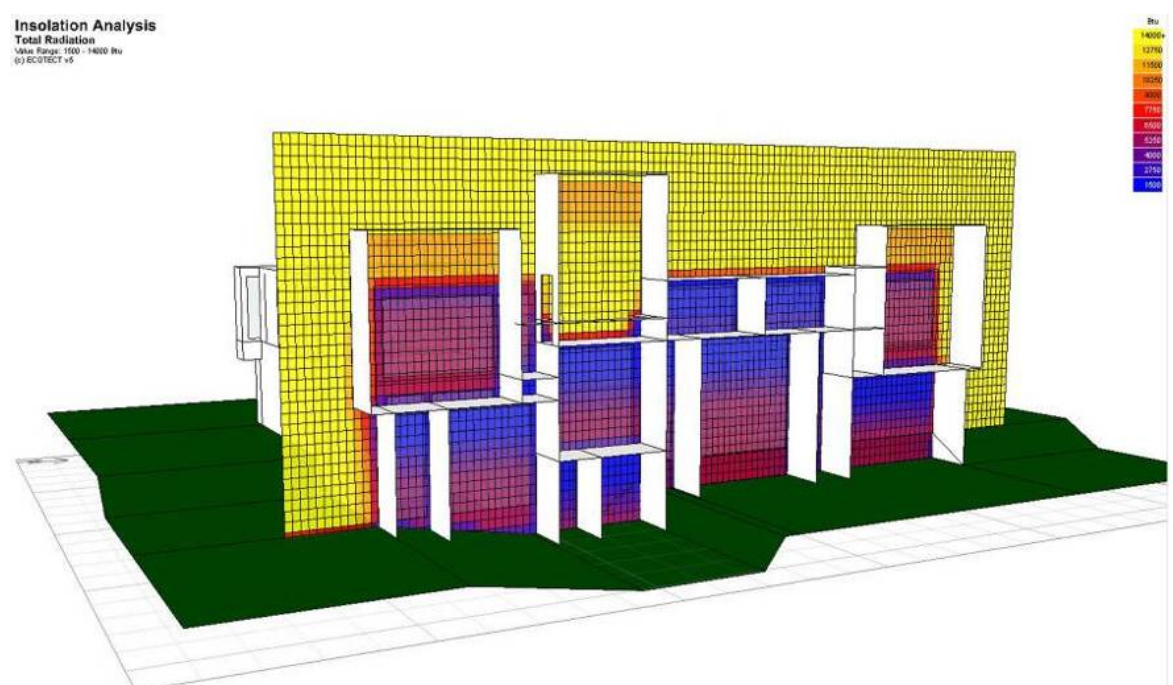

(a)

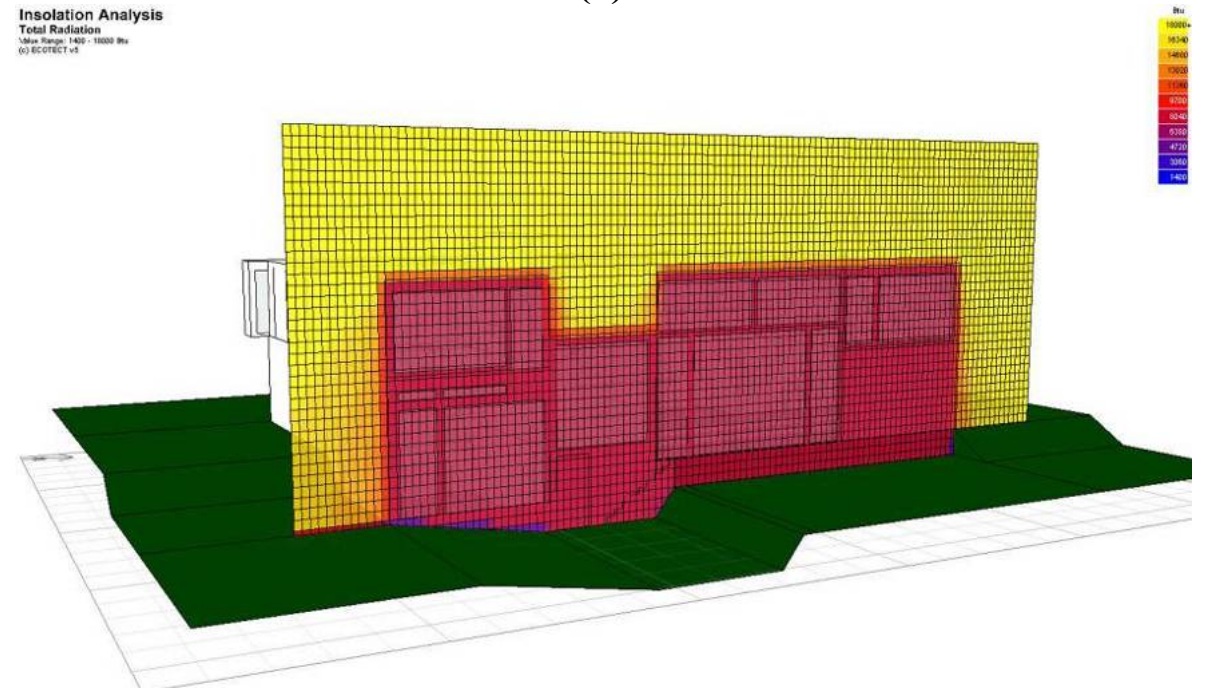

(b)

In Figure 5, an identical simulation is run for January 21st, where even in subtropical Florida average daily temperatures are $1.3{ }^{\circ} \mathrm{C}\left(52.4^{\circ} \mathrm{F}\right)$, Table 2 . The simulation demonstrates that when solar gain is desirable, the geometry and design of the shading screen does not interfere with the beneficial gains. These gains, although smaller because of the seasonal reduction of solar intensity, are still appreciable at 41 and $82 \mathrm{Wh} / \mathrm{m}^{2}$ (1500 to $\left.3000 \mathrm{Btu} / \mathrm{ft}^{2}\right)$. 
Figure 5. (a) January 21 st-Insolation with shading screen; (b) January 21 st - Insolation without shading screen.

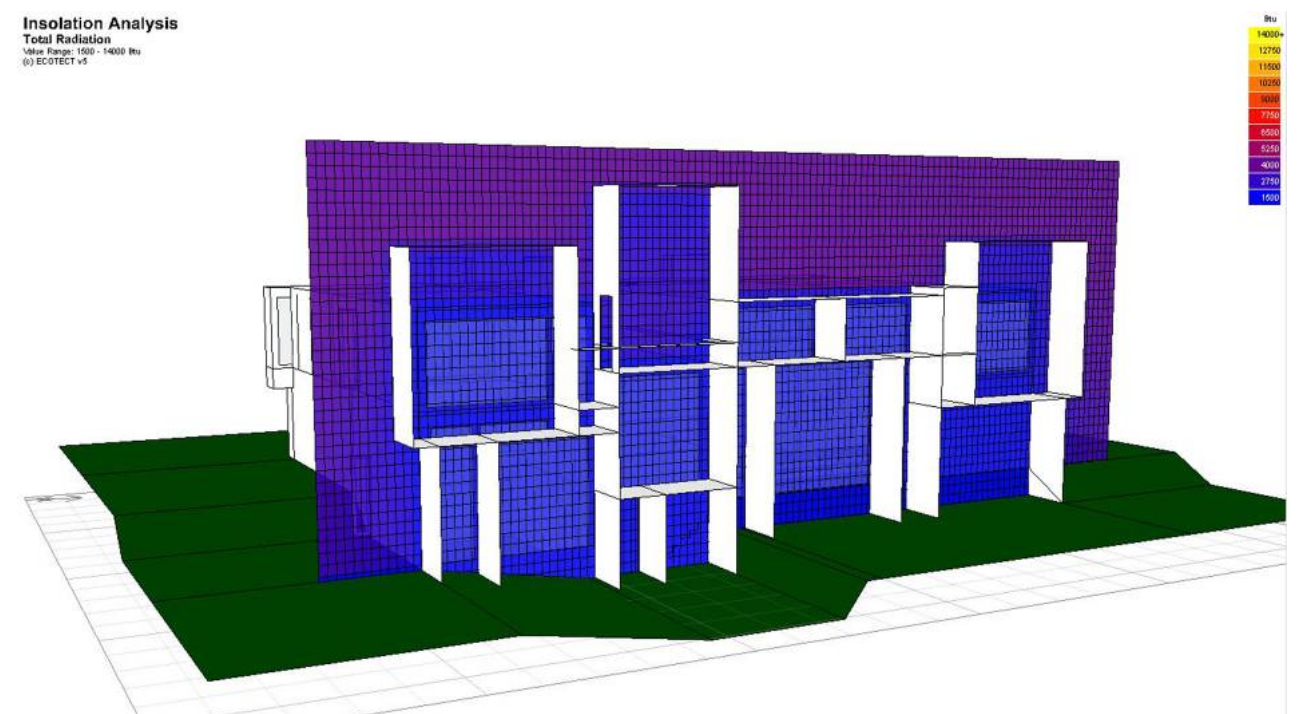

(a)

Insolation Analysis

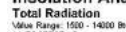

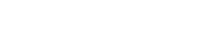

$=$

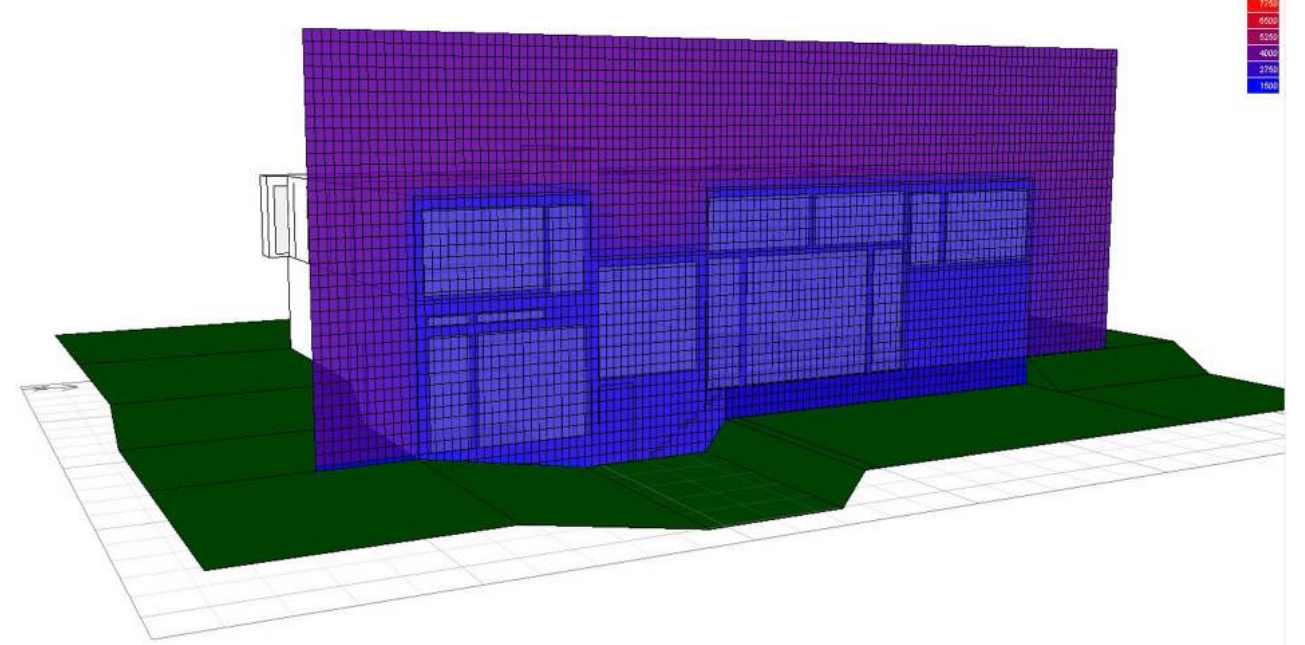

(b)

The two individual geometries that are of particular interest are the two screens on the upper level designed with voids above and to the sides of the glazing (see arrows on Figure 6, [9]).

There are two performance-based reasons for the existence of these voids, which respectively defend two bedroom spaces. The first is related to daylighting. In the latter part of the afternoon, when the sun is in the western sky, these spaces do not receive any direct sunlight and the bedroom windows are in deep shade. In summer this is beneficial from a cooling load perspective, but it is a negative from a daylight perspective. In winter, while the solar gains are allowed by the screens' geometry, the absence of direct sunlight into the room is still problematic. Both rooms are dependent on their eastern glazing for daylighting; the master bedroom, on the southern end of the residence, has one narrow slit window, $38 \mathrm{~cm}$ (15 min.) wide on the south wall. The bedroom at the north end does not have any additional windows. 
However, between 12:00 and 13:00 and sunset each day direct solar rays, from the west, penetrate the void and "light up" the screening device. This allows for diffused natural light to enter the living spaces, thereby increasing the lighting levels within the adjacent zones. The Ecotect model illustrates the penetration of direct sunlight from the west and tracks the light across the inner walls of the voids (Figure 7).

Figure 6. East Elevation.

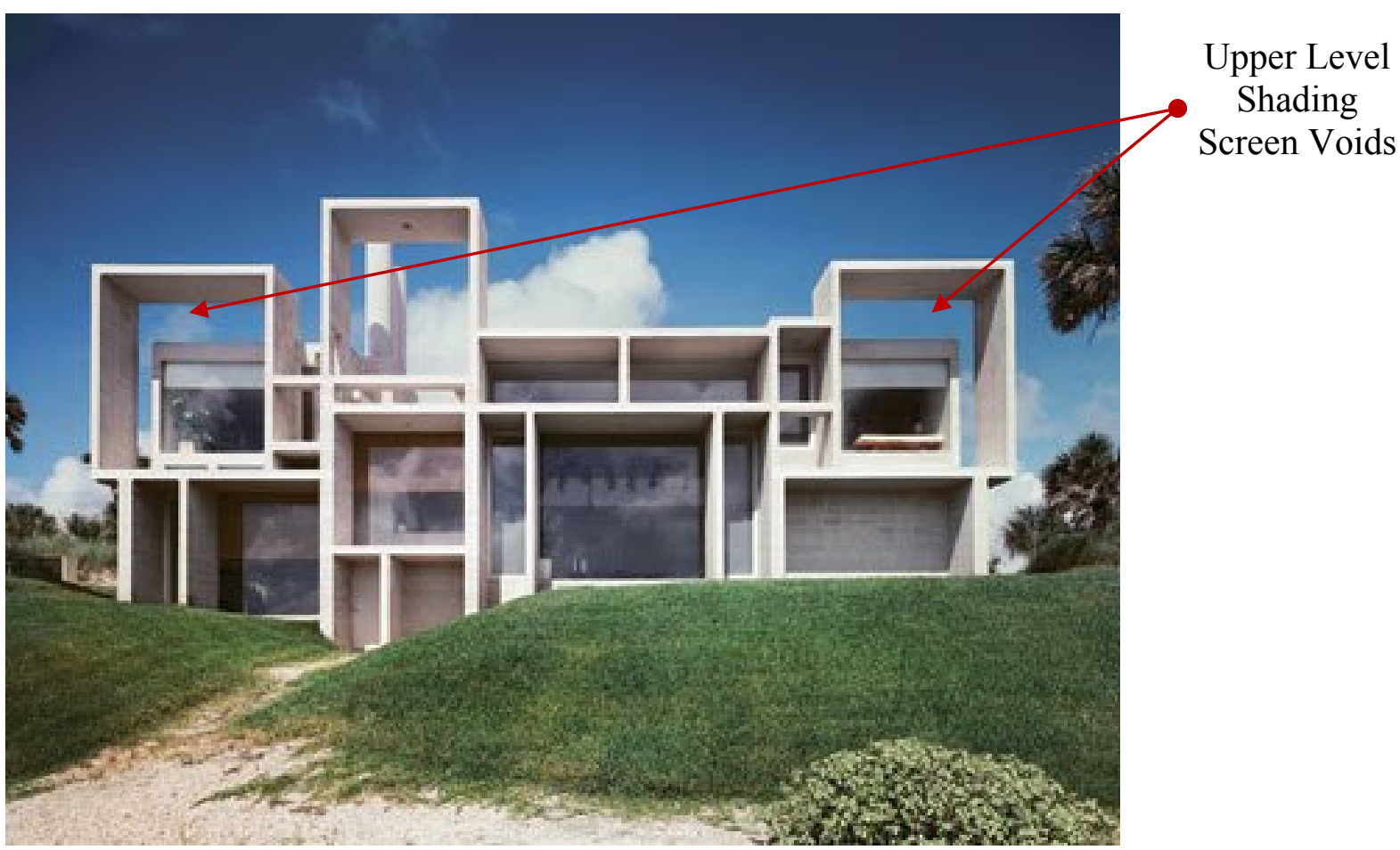

Figure 7. Angle of solar incidence through void; view from southwest.

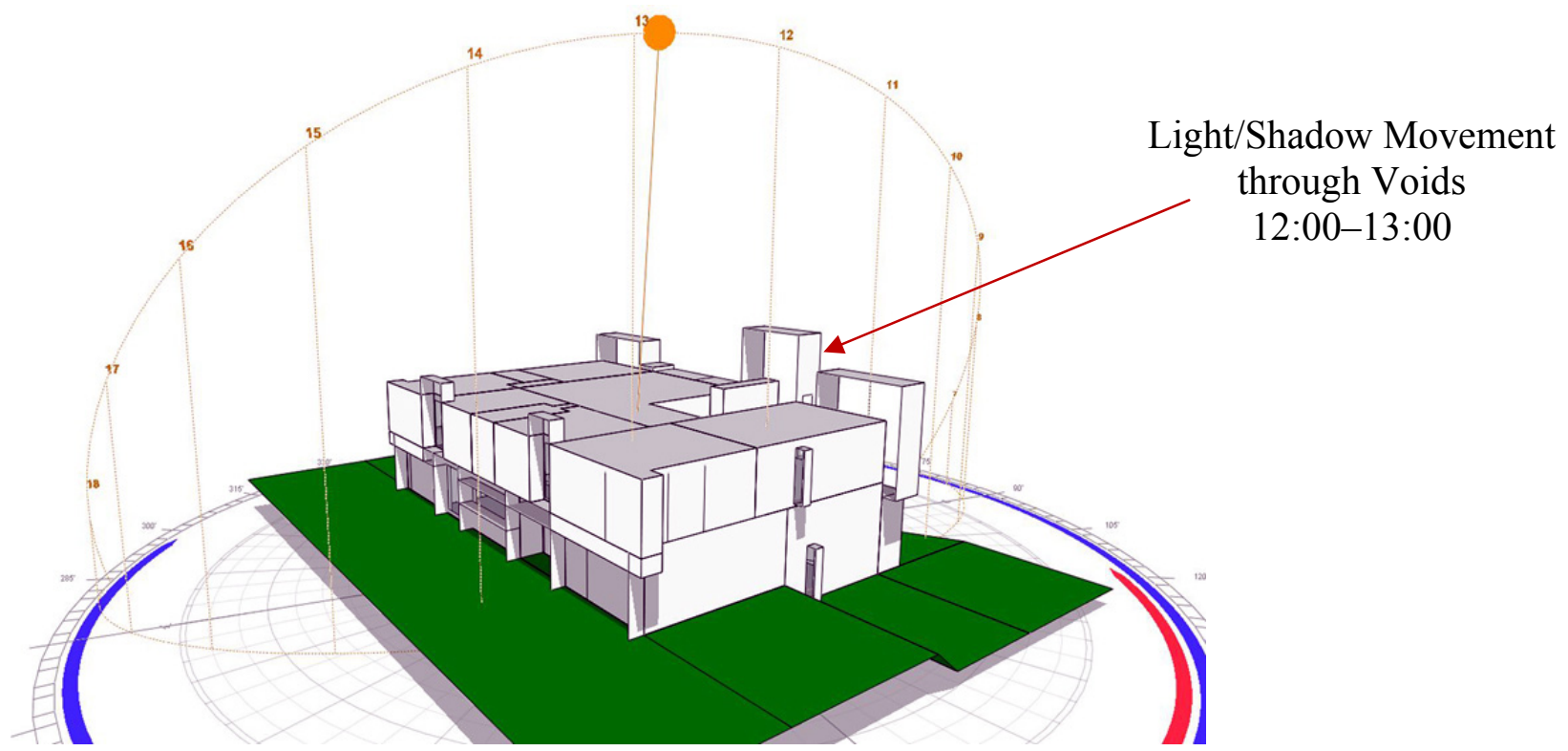

(a) 
Figure 7. Cont.

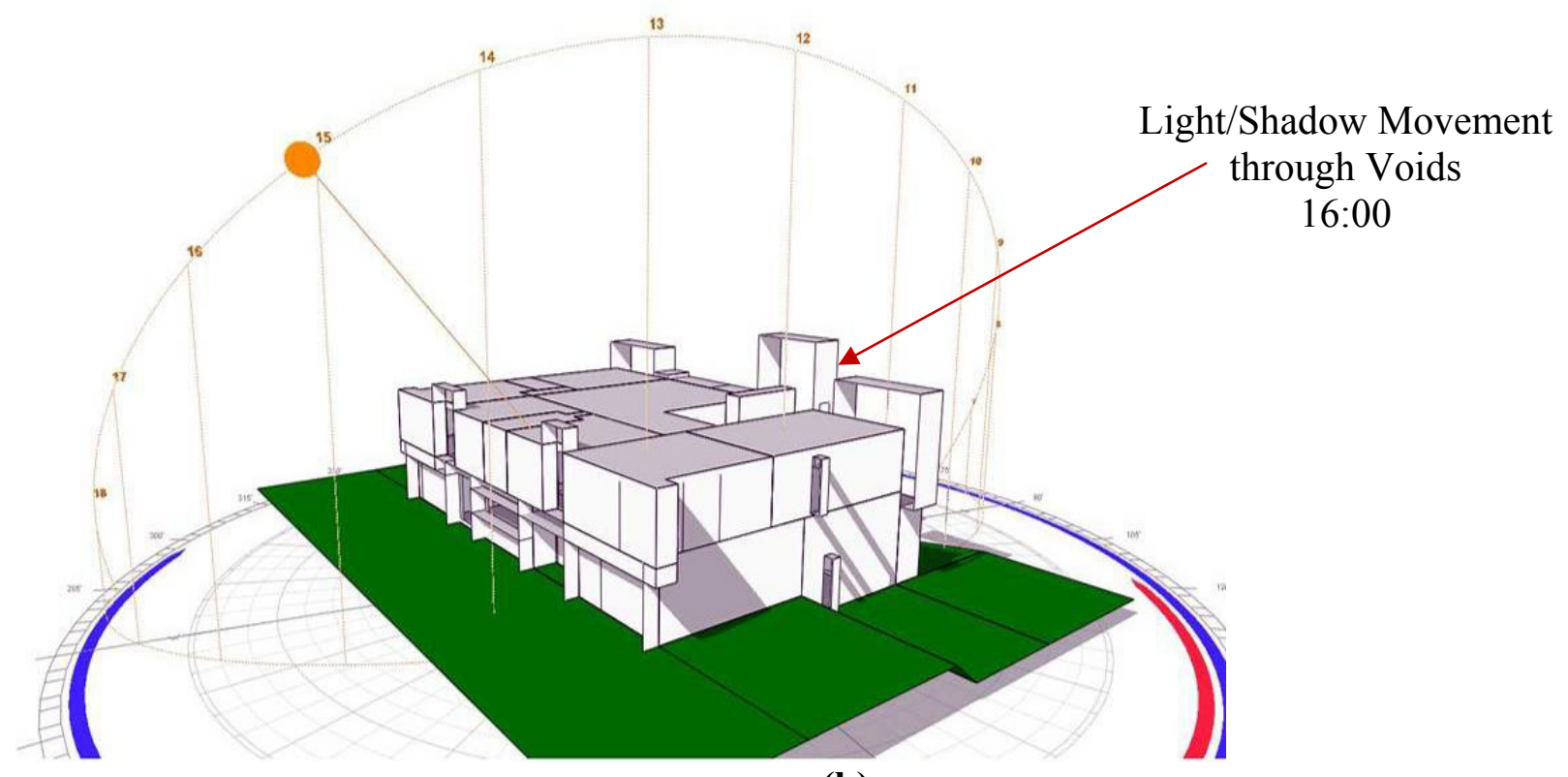

(b)

The effect is shown in Figure 8. The images shows that daylight penetration with the shading screen in place is both deeper into the room, $3 \mathrm{~m} \mathrm{(10} \mathrm{ft.)} v s .2 .3 \mathrm{~m}(7.5 \mathrm{ft}$.) with an increase of $33 \%$, and has greater intensity with an increase of $7 \mathrm{Wh} / \mathrm{m}^{2}\left(250 \mathrm{Btu} / \mathrm{ft}^{2}\right)$ at nodes of maximum penetration. It is of note that when a similar analysis is conducted for the eastern rooms on the first level, e.g., Sitting Well or Fireside Area, where shading screens do not possess voids; there is no change in diffuse radiation in the rooms either in distance of penetration or intensity with the shading screen present or absent.

Figure 8. Angle of solar incidence through void; view from southwest.
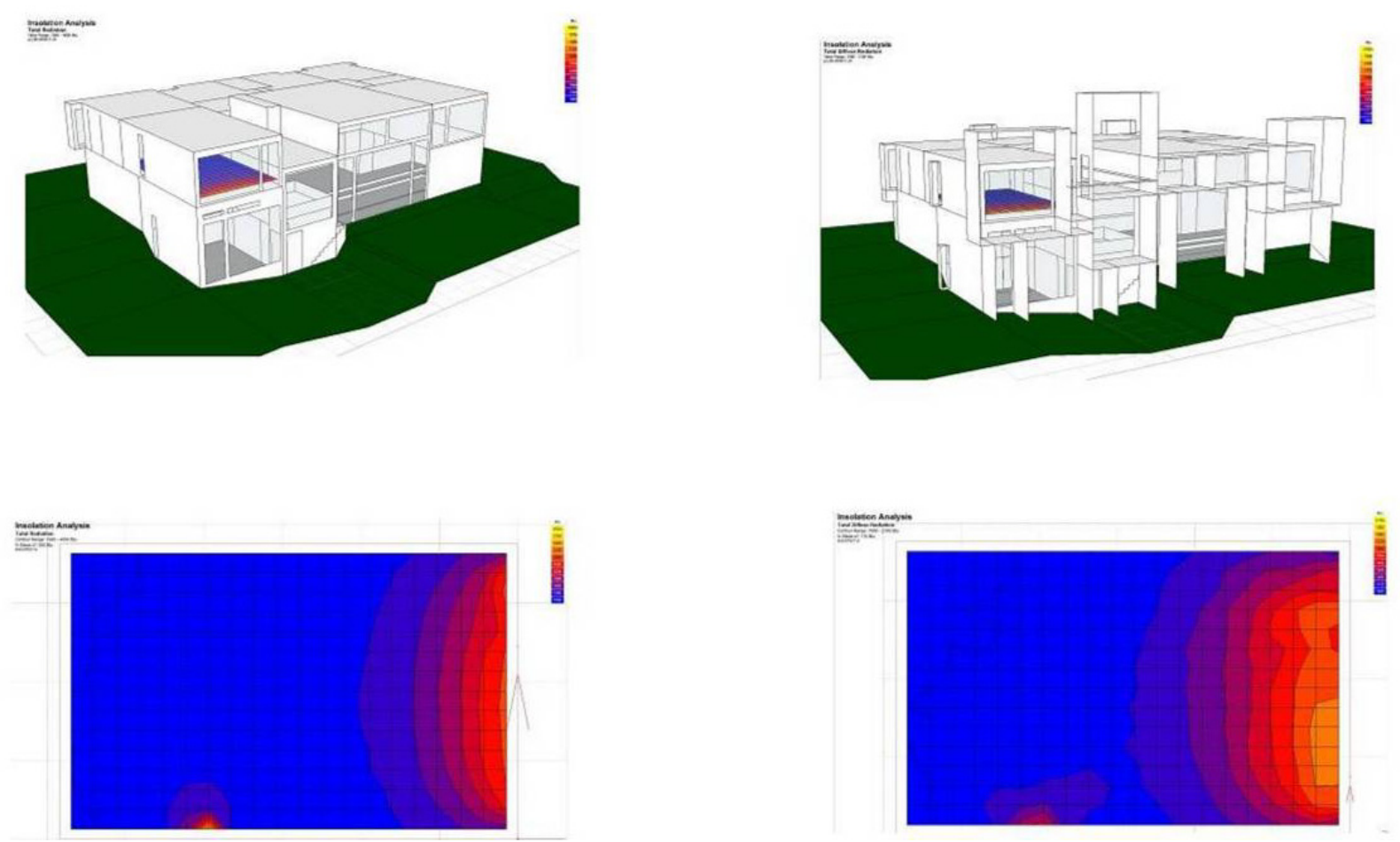
The second reason for the existence of the voids concerns ventilation and structural cooling effects. It is our intent to quantify these effects in a second study where the Milam House will be inserted and analyzed using another energy analysis software, EnergyPlus with DesignBuilder. This software will provide an opportunity to quantify a unique cooling strategy, i.e., the voids may allow for the screening devices to be ventilated, helping to reduce temperature build-up and minimize the temperature difference between the inside and the outside of the glazing surfaces.

\section{Analysis II: Shading Analysis of Windows}

The simulations illustrated in Figures 4 and 5 offered a macro look at the effect on the shading geometry on the eastern façade, but a more in depth analysis and examination of the impacts of these constructs on this façade is possible as well as an examination of the other ordinal facades.

There are four main screening devices that protect the major glazing areas on the eastern façade (Figure 9). The four constructs are analyzed for their shading effectiveness during critical hours of the exemplar summer day, 21 August. From Table 2, the critical cooling loads occur between 10:00 in the morning and 16:00 in the afternoon, which is when we expect to see the greatest benefit from the geometries.

Figure 9. East elevation shading analysis.

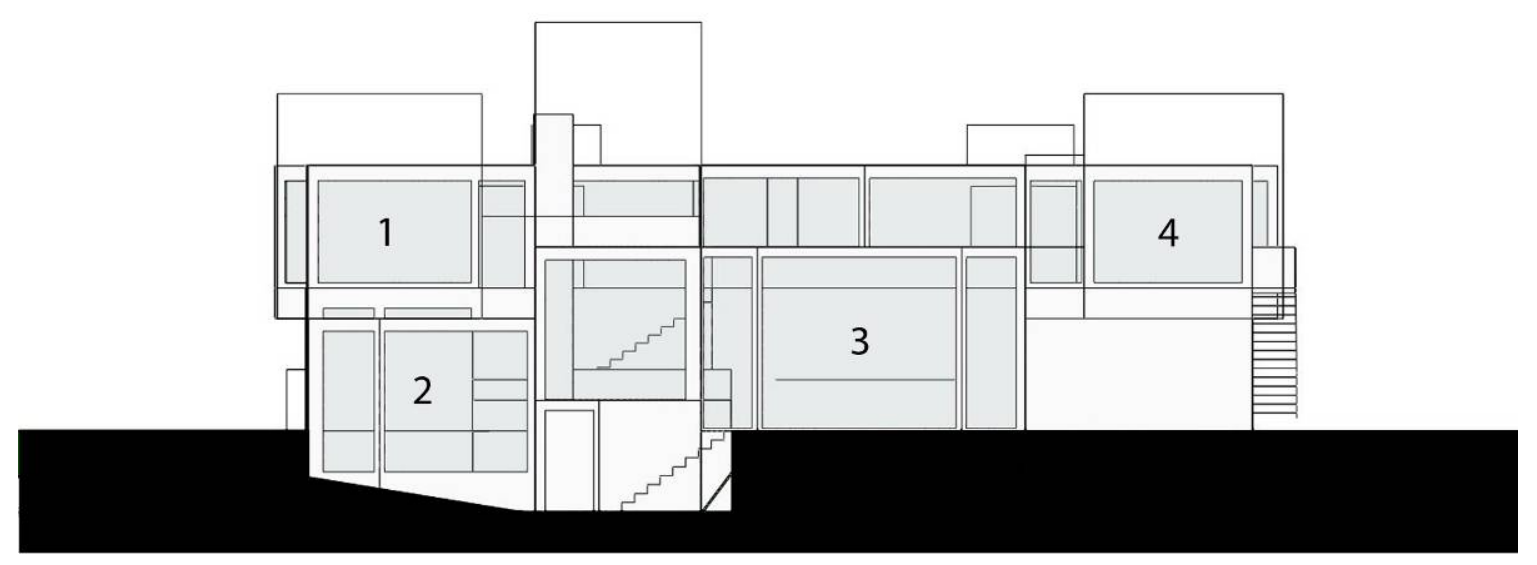

To quantify the effectiveness of the geometries of the screen as shading for the glazing, we compare two models for each of the four screens: (1) hourly solar exposure directly on the glazing area with the shading screen and (2) hourly solar exposure without the shading screen.

Our findings for the eastern facade (Figures 10 and 11) suggest that the screening devices are effective against incident solar radiation during the critical hours, and provide a degree of solar shading between the hours of 7:00 am and 12:00. Most importantly, during the critical two hours before noon, all four screening devices shade $100 \%$ of the eastern windows. In contrast, without the shading devices, the windows are completely exposed to incident solar radiation, with no protection against heat gain and glare. 
Figure 10. East elevation, Windows 1 and 2 hourly solar exposure.

Window 1

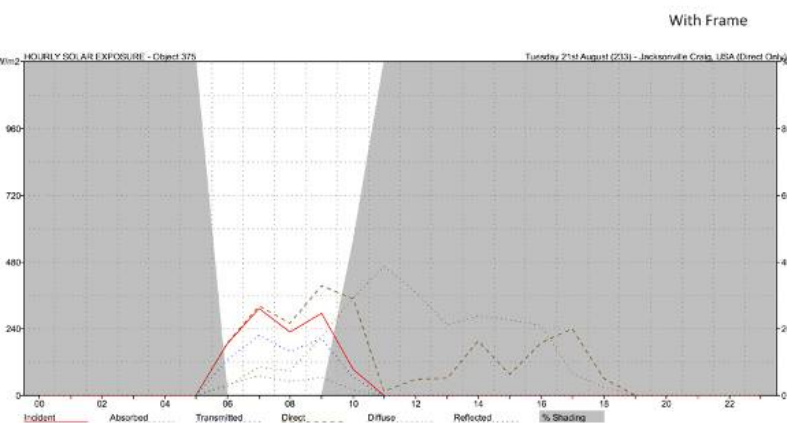

Without Frame

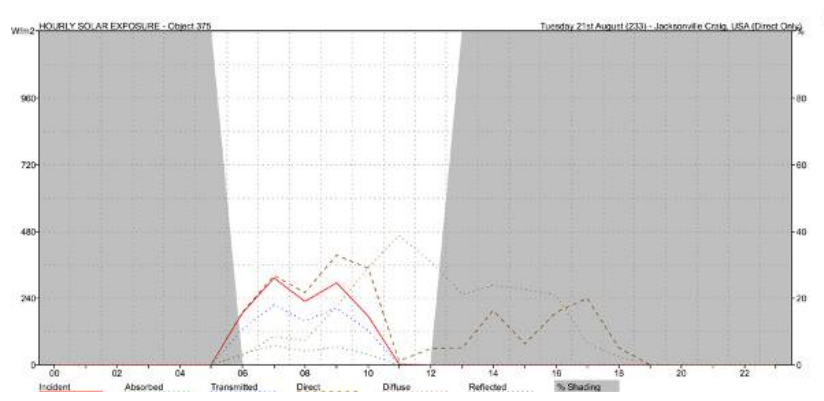

Window 2

With Frame

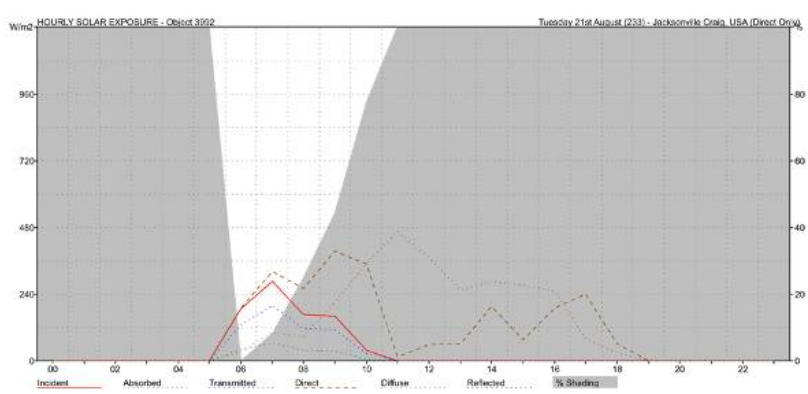

Without Frame

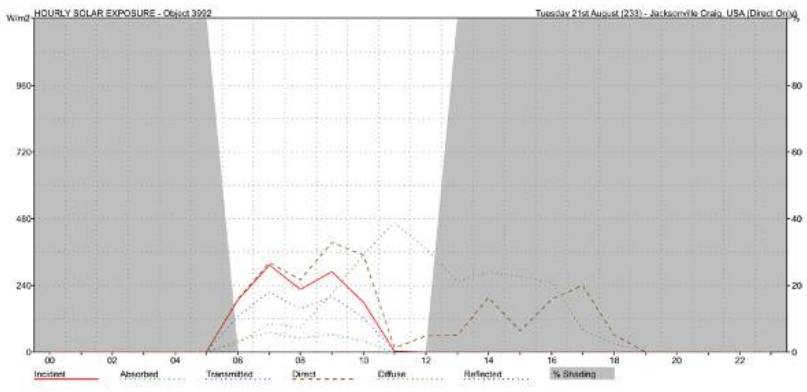

Figure 11. East elevation, Windows 3 and 4 hourly solar exposure.

Window 3

Window 4

With Frame
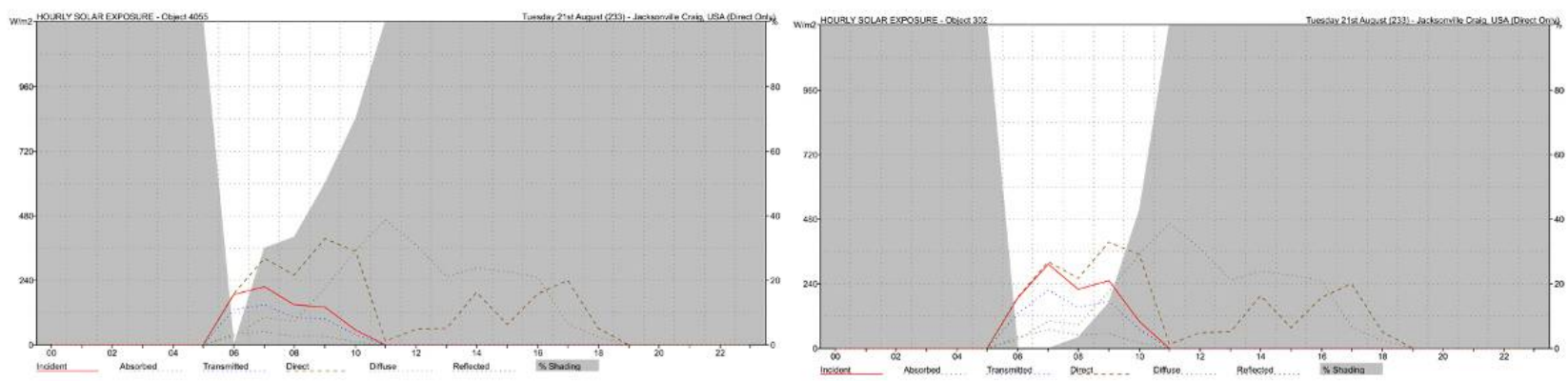

Without Frame

Without Frame
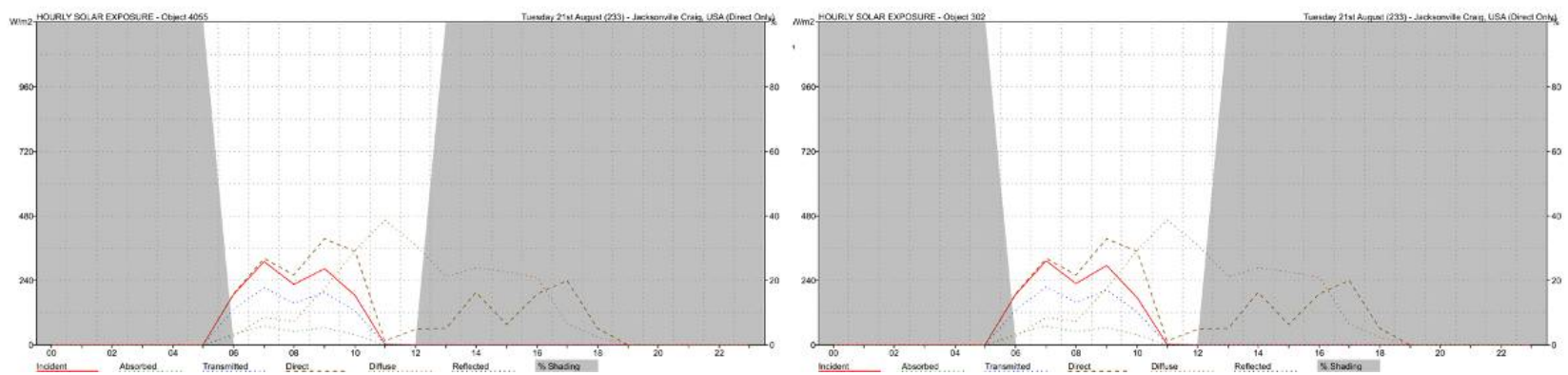

The western façade presents a more modest appearance with largely opaque walls containing few windows (Figure 12, [1]). The screening devices on this elevation are less dominant and provide little protection in terms of solar shading. As with the upper level of the eastern facade, the voids are also present, but are not deep enough to be used as a source of indirect natural light for the adjacent zones. 
They may offer some cooling effect due to air movement within the screening device, but it is not likely to be significant.

Figure 12. West elevation.

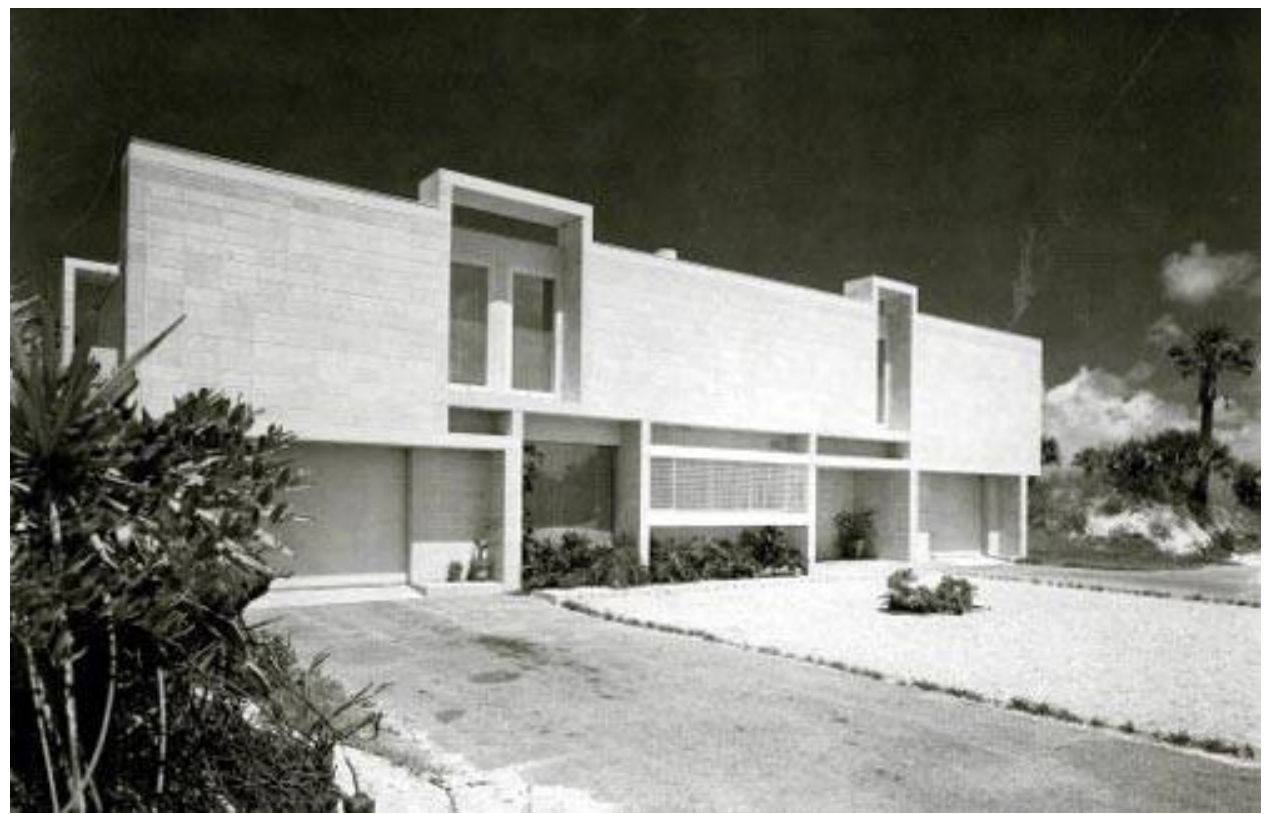

The shading effectiveness of the screening devices (Figures 13 and 14), on the western facade is minimal and major protection of the structure against heat gain from the western sun is offered by material choice and size, i.e., the heavy mass of the wall and smaller window sizes. The spaces adjacent to the windows are private zones for sleeping, bathing, or cooking, which are typically not heavily occupied during the hottest part of the day. Thus, due to the placement and organization of the main living spaces to the eastern side in the house, the west elevation is less critical in terms of shading and natural lighting design strategies.

Figure 13. West elevation shading analysis.

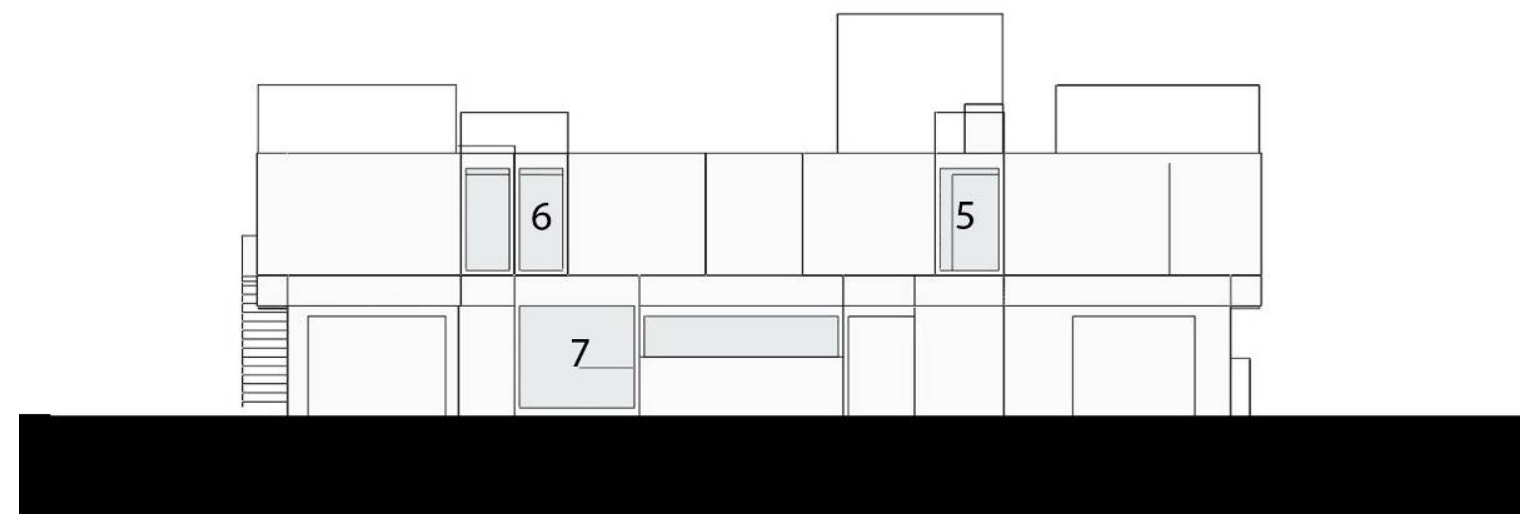


Figure 14. West elevation hourly solar exposure.
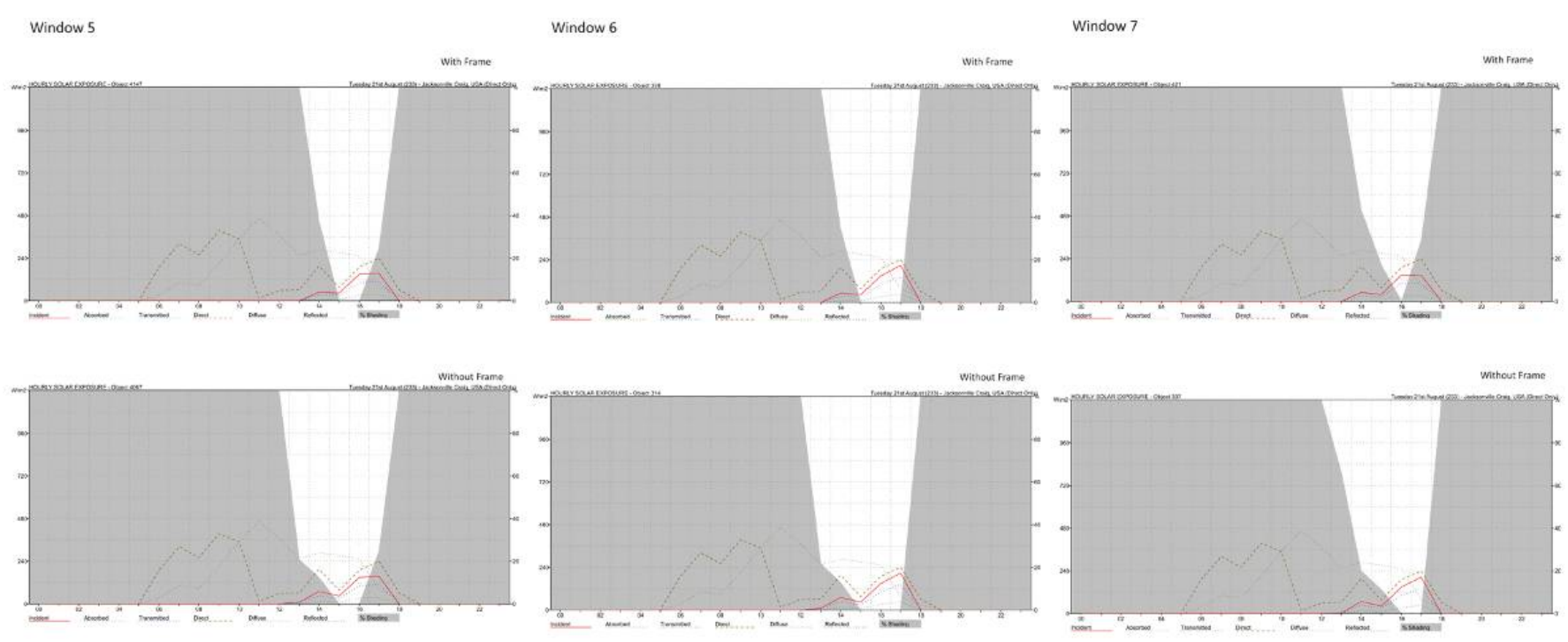

Northern and southern façades (Figure 15), by comparison, contain very few windows in lieu of structural elements such as an outdoor stairwell leading to the upper level. Neither of these two elevations have enough glazing to provide daylighting and were not analyzed for this study.

Figure 15. North \& South Elevations.

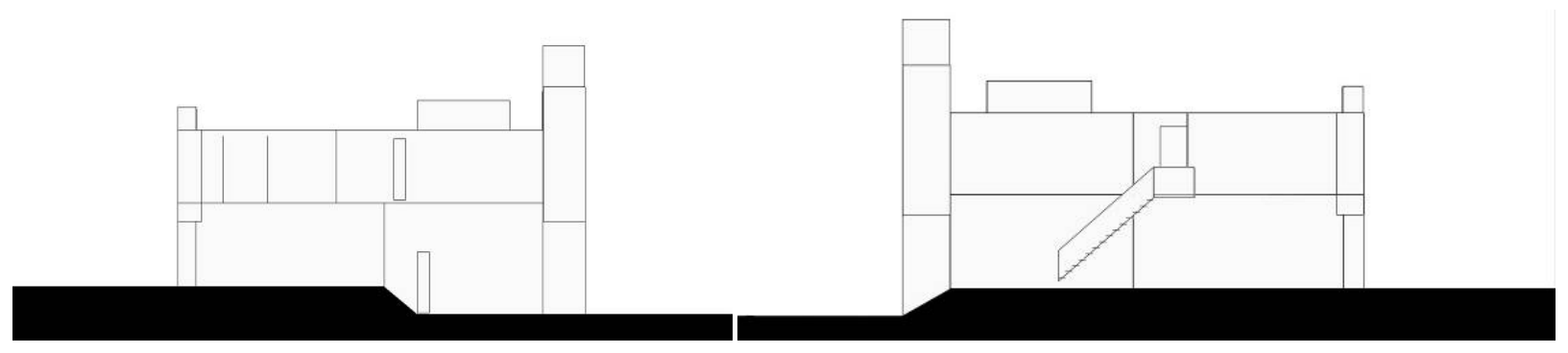

\section{Analysis III: Cooling Load Reduction resulting from Shading Screen}

The previous two analyses examine the impacts of the shading geometry on daylighting, insolation levels, and hours of solar exposure of glazing during an exemplar day, 21 August, in summer when shading, daylighting, and insolation effects are most pronounced. Using Ecotect's thermal analysis the heating and cooling loads as related to the shading construction are examined on a monthly basis for a typical year based on the weather file for Jacksonville (USA-Jacksonville-Craig.Field.722068_TMY3Florida.wea).

This analysis supplies evidence that in addition to the enhanced occupant comfort levels offered by increased daylighting, reduction of direct solar glare, and control of the eastern windows' radiation into the interior spaces (positive in winter; negative in summer) there are substantive reductions to the cooling loads and minimal increases to the heating loads.

Similarly to the previous analyses, in order to quantify the effectiveness of the geometries of the screen, we compare two models ((a) without the shading geometry in place and (b) with the shading geometry). For each model four monthly heating/cooling load analyses are run: (1) for all of the 
thermal zones in the residence, (2) for all of the adjacent eastern zones in the residence, (3) for the Main Living Space, and (4) for the Master Bedroom. (Figures 16, 17, 18 and 19).

Inputs for all analysis are consistent. Heating and cooling systems are in active mode without passive ventilation (windows are fixed). Thermostat setpoints were $18{ }^{\circ} \mathrm{C}\left(64.4{ }^{\circ} \mathrm{F}\right)$ to $26{ }^{\circ} \mathrm{C}\left(78.8^{\circ} \mathrm{F}\right)$. Humidity is set to $50 \%$. Clothing level is set to 1 clo. Occupancy is typical for the room type. Air Change is set to $.5 \mathrm{ACH}_{\text {nat }}$ (reasonable for a concrete block and slab structure with fixed glazing).

In all instance cooling loads are reduced: Master Bedroom by $10.1 \%$, adjacent eastern rooms by 9.1\%, Living Room by $7.6 \%$, and all thermal zones by $7.2 \%$. The heating load for all thermal zones increased only by between 3\% resulting in an overall annual energy reduction, precipitated solely by the eastern shading geometry of $4.2 \%$.

Figure 16. Monthly heating/cooling loads for all zones.

(a) Without shading devices.

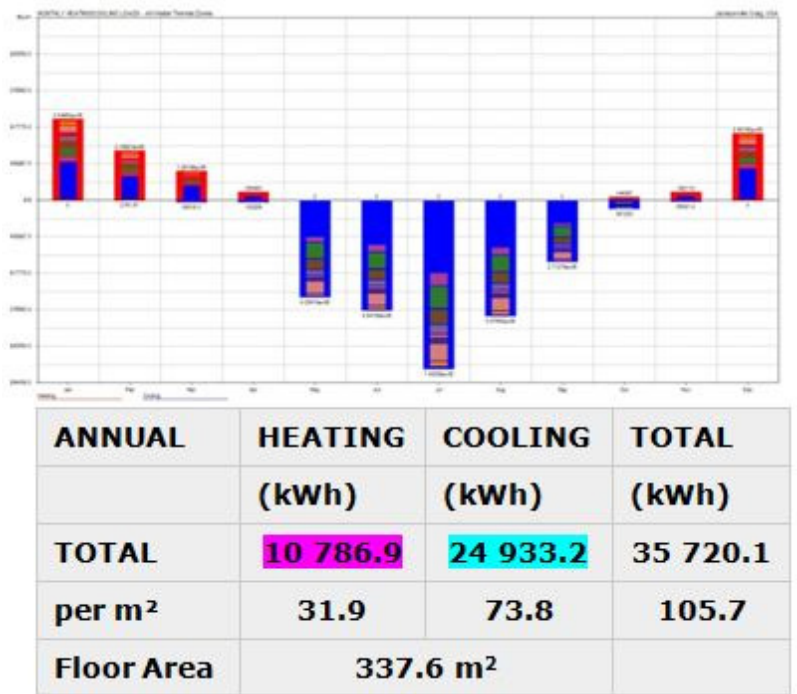

(b) With shading devices.

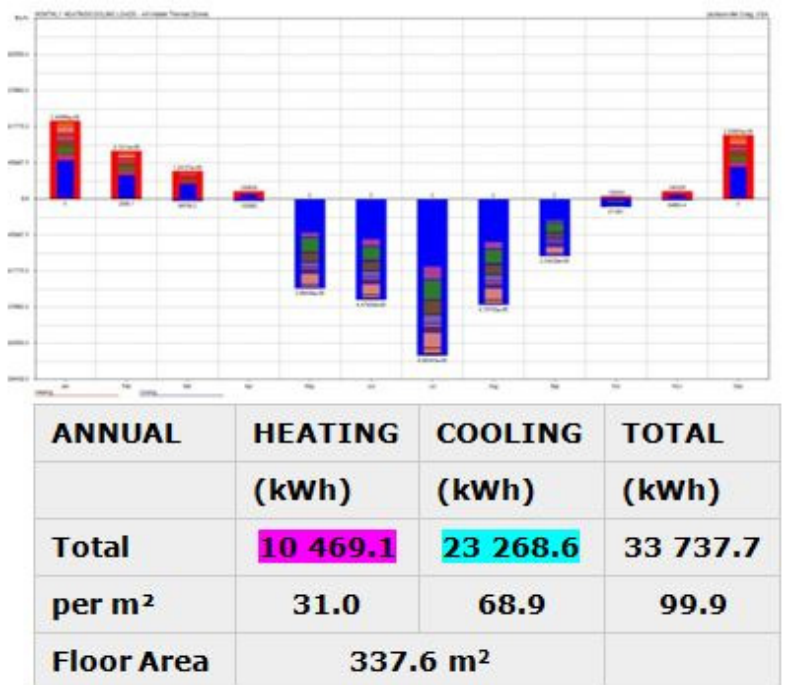

Figure 17. Monthly heating/cooling loads adjacent eastern zones in the residence.

(a) Without shading devices.

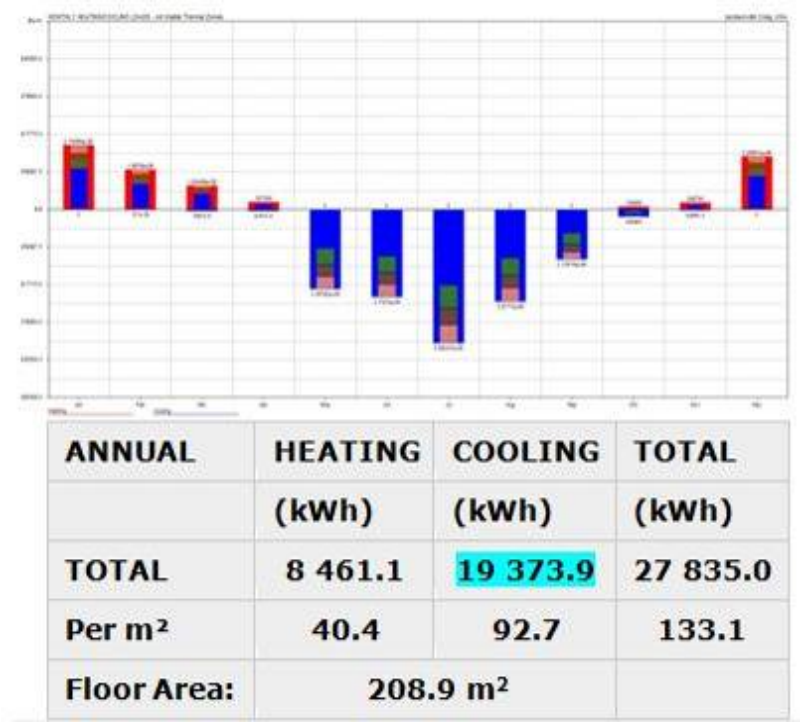

(b) With shading devices.

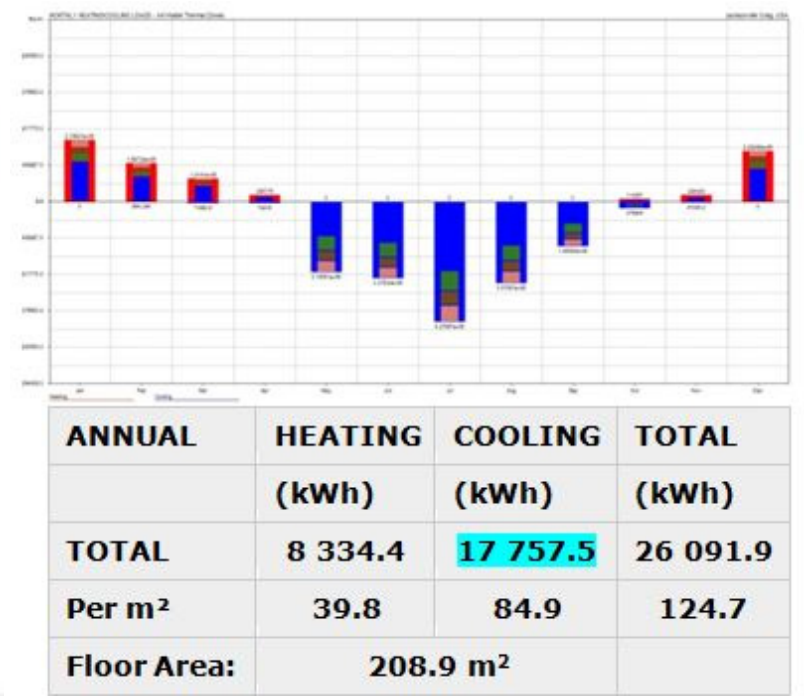


Figure 18. Monthly heating/cooling loads for main living space.

(a) Without shading devices.

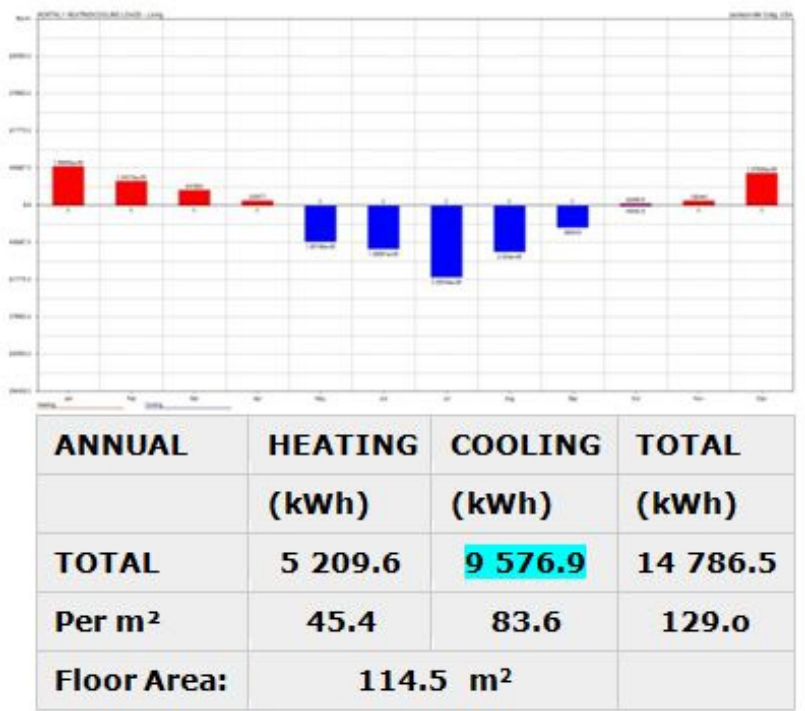

(b) With shading devices.

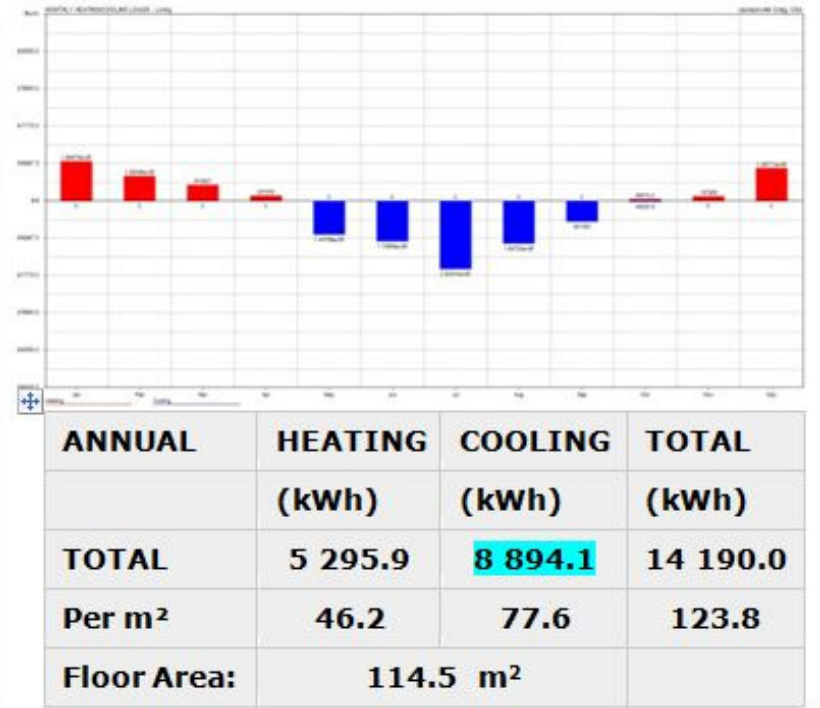

Figure 19. Monthly heating/cooling loads for master bedroom.

(a) Without shading devices.

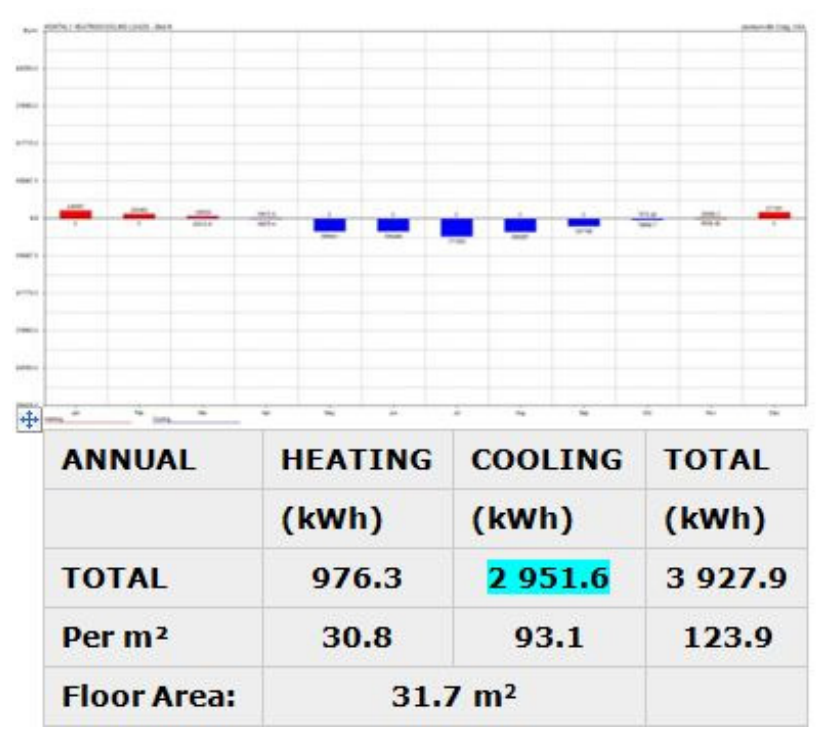

(b) With shading devices.

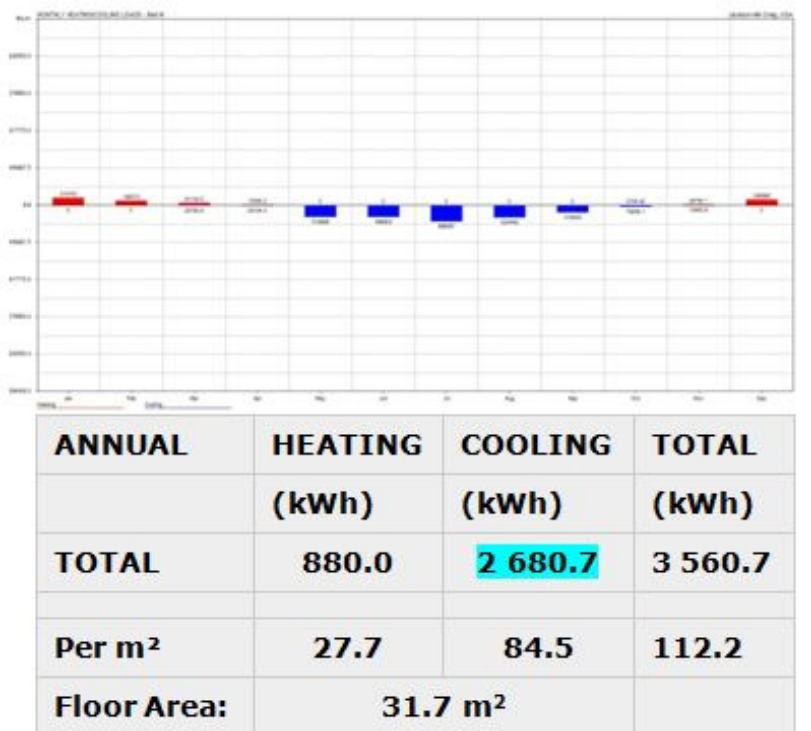

\section{Conclusions}

As a whole, the building's orientation towards the ocean on the east, extensive sun screening, concrete construction, and design are effective in minimizing heat gains within the structure.

First, the building's eastern orientation provides cooling breezes from the ocean air currents that ventilate the site. The three dimensional sunscreen added to the eastern façade helps shade the eastern windows in the latter part of the morning when the sun's heat is increasing while still allowing light to penetrate the structure. Natural light is maximized by placing most of the primary living quarters near the easternmost, highly glazed façade, where the voids in the shading structure augment the daylighting in the eastern bedrooms. The shading structure also provides a critical buffer against the 
heat from rising sun and the day's direct solar gain translating into real energy savings in the form of reduced cooling loads. Rooms that are less frequently occupied, such as secondary bedrooms, kitchen, and bathrooms, are located on the western side and are minimally glazed, to block the harsh western afternoon sun.

The open floor plan enables cross ventilation through the spaces of the house guided by the central air conditioning units rather than by the windows, which are inoperable [3]. Furthermore, the sunken areas and multiple levels allows cooled air to gather in living spaces, while heated air is drawn upwards and circulated through the building's air conditioning system.

The porous concrete blocks contain air pockets that reduce the formation of thermal bridges, aiding in keeping the building's air conditioning within the structure and preventing outside heat from intruding. The concrete block construction has an overall wall thickness of $20 \mathrm{~cm}$ (8 in.), providing a minimal, but adequate thermal barrier between interior and exterior.

The physics of heat, moisture, and air flow indicate that the Milam residence demonstrates both positive and negative characteristics. Because of the high humidity and temperature of the climate, keeping cool air inside while still allowing ventilation is critical to controlling the temperature and humidity of the structure. However, the potential of moisture to condense within the concrete might prove to be a durability problem as cooled air from the structure's interior and warm air from outside meet, precipitating condensation within the exterior wall assembly.

The Milam Residence's design, orientation, spatial organization, and selection of materials succeed in providing passive cooling and natural lighting for the major eastern facade. Further analysis is needed to investigate the thermal efficiency of the structure, particularly with regard to moisture intrusion due to condensation within the block walls. Solar shading and daylighting are beneficial in this climate, but the construction techniques and detailing may prove to introduce some limitation to the building's overall energy efficiency.

The essence and focal point of the structure is its monumental shading screen. Without that geometry Rudolph's iconic structure is reduced to a reductionist massing coordinated with ingenious integration of levels, an astute choice of organic materials, and a spectacular site. All of which would have resulted in an excellent workmanlike project — but not an icon. The incorporation of the geometry of that monumental shading screen - extending out of floor plates and framing the basic design with like materials - lifts the project to iconic stature. The insights gained by this paper demonstrate the extent that Rudolph incorporated effective passive strategies into his design.

\section{Acknowledgments}

The authors would like to thank Arthur Milam for his kind feedback and responses to our various queries about his home.

\section{Conflict of Interest}

The authors declare no conflict of interest. 


\section{References and Notes}

1. King, Joseph; Christopher, D. Paul Rudolph: The Florida Houses; Princeton Architectural Press: Princeton, NJ, USA, 2005; p. 146.

2. More Paul Rudolph Houses-Exteriors and Interiors. WordPress: Cincinnati, OH, USA, 2009. Available online: http://blog.ounodesign.com/2009/05/26/more-paul-rudolph-houses-exteriorsand-interiors (accessed on 8 December 2010).

3. Howey, J. The Sarasota School of Architecture, 1941-66; MIT Press: Cambridge, MA, USA, 1997; p. 99.

4. Millard, B. Magnificent brute. RIBA J. 2008, 115, 38-42.

5. Rudolph, P. Architecture of Paul Rudolph; Praeger Publishers. Inc.: New York, NY, USA, 1970; p. 70.

6. Weston, R. Plans, Sections, and Elevations: Key Buildings of the Twentieth Century; Laurence King Publishing: New York, NY, USA, 2004; p. 136.

7. National Weather Service. NOAA: Jacksonville, FL, USA, 2011. Available online: http://www.weather.gov (accessed on 8 December 2010).

8. Weather Underground. undergroud.com: Jacksonville, FL, USA, 2010. Available online: http://www.wunderground.com/US/FL/Jacksonville.html (accessed on 8 December 2010).

9. Paul Rudolph Foundation Homepage. Available online: http://paulrudolph.blogspot.com (accessed on 8 December 2010).

(C) 2011 by the authors; licensee MDPI, Basel, Switzerland. This article is an open access article distributed under the terms and conditions of the Creative Commons Attribution license (http://creativecommons.org/licenses/by/3.0/). 